\title{
LXII. On the artificial production of cold
}

\section{Richard Walker Esq.}

To cite this article: Richard Walker Esq. (1828) LXII. On the artificial production of cold, Philosophical Magazine Series 2, 3:18, 401-406, DOI: 10.1080/14786442808674677

To link to this article: http://dx.doi.org/10.1080/14786442808674677

曲 Published online: 10 Jul 2009.

Submit your article to this journal $\widetilde{ }$

山 Article views: 12

Q View related articles $\sqsubset$ 
'T HE'

\section{PHILOSOPH ICAL MAGAZINE}

A N D

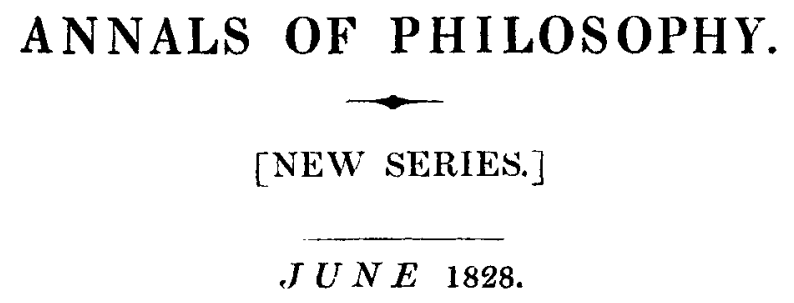

LXII. On the Artificial Production of Cold. By Richard
WaLker, Esq. of Oxford.

To the Editors of the Philosophical Magazine and Annals.

Gentlemen,

$\mathrm{T} T$ is now forty-one years since my discoveries on the "arti1 ficial production of cold" were first made public by their appearance in the Philosophical Transactions for the year 1787, and several succeeding volumes. Passing over what has already been published respecting them, I shall proceed to a detail of a few other circumstances as a kind of appendix, which I have for several seasons intended to offer for publication, had not other matters, as professional avocations and professional communications, too much engaged my attention to allow of it.

Immediately on the announcement of the discoveries as above stated, I received various proposals from respectable persons respecting their practical utility in this country. I answered these by a declaration that wherever natural ice could be obtained and preserved, this must ever supersede the use of the artificial means alluded-to. It is true that $I$ had an eye to their application in hot climates, as between the tropics; and so soon as my experiments became public, a treatise on the diseases of tropical climates appeared from the pen of Dr. Moseley, who fixed upon one, which he considered the most appropriate, and strongly recommended its adoption as a very valuable acquisition as well in a medicinal point of view, as a luxury.

Relinquishing, from various causes, the design of applying them myself to any such purpose, I took care however to point

Nerw Series. Vol. 3. No. 18. Jine 1828. 3 F out, 
out, in my original communications, the complete efficiency of them for such intention to their utmost extent, and the best mole, as it appeared to me, of appiying them in hot climates.

Understanding, a few summers ago, that a manufactory had been established for preparing ice-creams, as well without the use of ice, as with it; and likewise for -making for sale an apparatus for the purpose, -I was induced to visit it. I examined the apparatus, - a very appropriate one for the purpose, and likewise the freezing powder, which I instantly recognized to be the weakest in power of my various compositions for the purpose, but possessing the advantage of being readily recovered repeatedly for the same purpose with undiminished effect. This powder, by its taste and appearance, I found to be a mixture of sal ammoniac and nitre, which $I$ was informed was repeatedly recoverable in a fit state for refrigeration. I originally exerted every effort, in vain, to increase its power by the addition of a third ingredient, possessing likewise the advantage merely by evaporation to dryness, of being repeatedly recovered for the same use. This powder, as related in my original communications, consists of equal parts by weight of sal ammoniac and nitre. By way of test, I recovered it by evaporation twelve times, without any abatement of its efficacy, as originally stated*.

It is unnecessary to enter into a description of the apparatus just mentioned, or the principle and mode of its application, especially as the whole is embraced in the following statement.

A circumstance occurred here (at Oxford) which occasioned the method to be put to the test of useful application. A confectioner, happening in a scarce season to be unprovided with natural ice, applied to me for assistance. I assured him that in the large way (as I have stated in my original communications) the best method was to freeze water first, and then to use the ice in the usual way for freezing creams. Accordingly an apparatus of large dimensions, of rather an oblong form, was made of tin (fitter for the purpose if cased with wood) consisting of channels so constructed that the water to be frozen should be subjected to the freezing mixture on both sides. This, properly prepared, was placed in a cool cellar during the night, and early in the morning (the temperature in the open air in the shade in the day-time being above $80^{\circ}$ ) the ice was collected, which amounted to several pounds in weight. This ice, which was as limpid as the finest flint-glass, was applied in the usual way, and with the apparatus ordinarily used by confectioners for the purpose of freezing creams, and the mixed

* The manufactory alluded-to is at "No. 41, New Bridge-street, Blackfriars, London (late Patterson's), now Armstrong's." 
powder, of which he had procured an adequate quantity, repeatedly recovered by evaporation over his hot iron plates, for fresh use.

I shall now present the immediate object of my present communication; viz. what I consider to be the best mode and fittest apparatus for cooling wine in summer, for freezing creams in the small way for private use, and likewise for freezing a small portion of water, merely as an experiment for public or private exhibition.

The drawing annexed (Plate VII.) is designed to represent on a small scale the construction and exact proportions of each freezing apparatus, and likewise the construction and form of the apparatus for cooling wine.

Fig. 1. is an apparatus for freezing water on the smallest scale, as above mentioned, in the hottest weather. The vessel for containing the freezing mixture is three inches and a half in width, and its height equal in measure to its width; and the tube for containing the water to be frozen five-eighths of an inch in width, and reaching, as represented, very near to the bottom of the vessel : there is likewise a rim or continuation of the vessel, without a bottom, to insulate it from the table or stand it rests upon. The apparatus itself consists of two parts; viz. the vessel for containing the freezing mixture, and its cover, in one piece with the tube, fitting close over it (represented together in the drawing). When the water is frozen, upon taking off the cover and wiping the tube, the solid ice will have become detached by the heat, and on inverting it drop out.

The process may be known to be conpleted by the going off or melting of the hoar-frost which exhibits a curious appearance outside the apparatus.

Fig. 2. consists of an apparatus in one piece; viz. the vessel for containing the cooling mixture, and the cup or can (if I may so call it) for receiving the decanter, its top rising somewhat above the height of the vessel for an obvious reason, with a cover that will admit of easy removal (in the drawing represented together). This apparatus likewise has an appendage or rim like the former, to insulate it from the table :-it may be convenient to be possessed of a couple of these.

Fig. 3. The apparatus for freezing creams, in which the freezing mixture is to act on both surfaces of the part containing it, as being more oconomical and expeditious, is not so simple. This however consists only of two parts; viz. the vessel for containing the freezing mixture; and a cover, to which is attached, in the same piece (instead of a tube or cup as in fig. 1.), a concentric annular cavity or chamber, in which the 


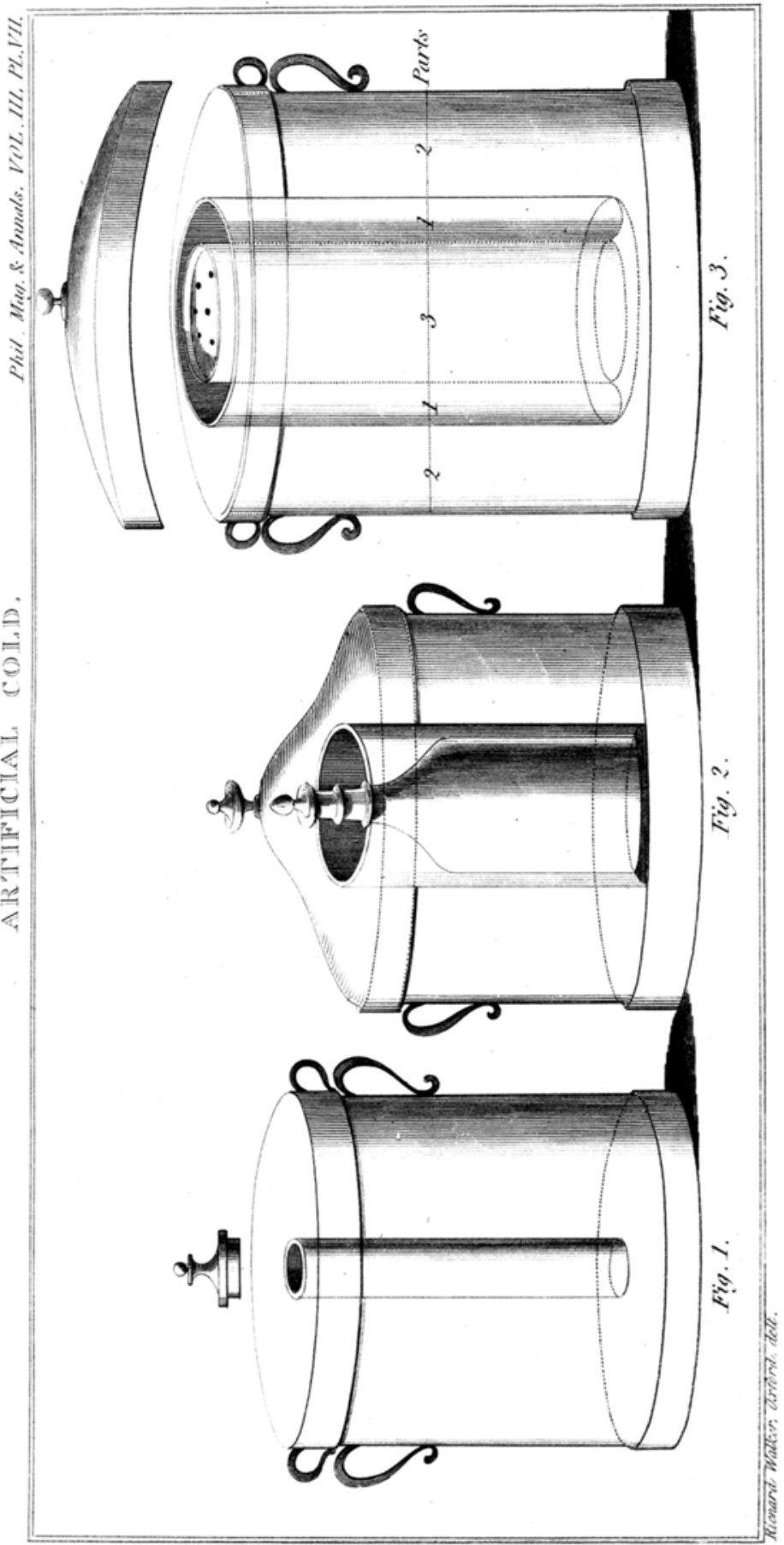


prepared cream is to be frozen: this cavity, forming a circle within the vessel itself, is open at the top, as represented, and of course closed at the bottom, and reaching very nearly (as the tube in fig. 1.) to the bottom of the vessel : this secondary part, as likewise represented, fits close as in fig. 1. over the vessel containing the freezing mixture. The proportions of the apparatus when together are thus: The outer space in width, two parts all round; the middle space, or that which contains the cream, one part all round; and the inner space three parts in width, - this serving as a general scale of proportions for an apparatus of any size. The proportions for an efficient apparatus, as my own, may be: for the first space ten-eighths of an inch (one inch and one-fourth); for the second, five-eighths of an inch; and for the third space, fifteen-eighths, or rather two inches, making the width of the apparatus itself somewhat above five inches and a half; its height being equal to its width, a projecting rim at the bottom likewise to insulate it from the table. It will be perceived that in the figure there are seven very small holes or apertures in the central part of this cover (one in the centre and six round at due distances), just sufficient for the escape of the air, to admit of the ascent of the freezing mixture in the middle part of the vessel. This apparatus is somewhat elevated at the top, or slightly convex, and the part in which the apertures are placed guarded by a shallow rim to prevent an accidental running-over of the mixture into the part containing the cream. This apparatus should be furnished (as expressed in the figure) with an outer cover similar, but less elevated, to the one at fig. 2. Previously to use it will be proper to ascertain the quantity of liquid the apparatus will contain when together, and mark its height; likewise the proportion of the ingredients for furnishing a given quantity in measure should be known. Thus, if the three salts are used (which I would recommend to a private individual, always doing so myself, although these cannot be recovered for future use, but being more efficacious than the two only) for each pint, small or old measure, will be required of sal ammoniac and nitre (each equal parts by weight reduced together into fine powder) six ounces, and of Glauber's salt, in clear crystals and dry, four ounces and a half, freely reduced to fine powder, or kept from the access of air, and in a separate parcel from the former; and water ten ounces, or enough to make up one pint in measure when added to the former ingredients : $\rightarrow$ of course, the whole must be well stirred together, and expeditiously, before introducing that part of the apparatus which contains the article to be frozen, and occasionally afterwards, till the object is completed, avoiding as much as possi- 
ble any accidental accession of heat. A freezing mixture composed of sal ammoniac and nitre with water, all at the temperature of $50^{\circ}$, to which temperature, or nearly so, they may all be reduced by water from a pump by drawing off a sufficient quantity first, will from $50^{\circ}$ produce a cold of $22^{\circ}$ below the freezing point, and with the addition of Glauber's salt to $28^{\circ}$. The confectioners find a degree of cold at $12^{\circ}$ or $15^{\circ}$ below the freezing point sufficient for their purpose; but it must be recollected that the cold produced by salts dissolved in water is not so durable as with ice and salt ; the duration of the refrigerating power in the above mixtures will of course be in proportion to the quantity and thickness of the apparatus. In the way the confectioner managed, the mixture in the apparatus retained its freezing property till the morning: my usual way is, in extreme hot weather, to place the vessel containing the powdered salts in the coldest water drawn from the pump previously; but in the ordinary way it will suffice to add the cold water without the above precaution: it may be advisable to be provided with a second quantity of the ingredients to preserve the cold by a renewal of the mixture. The drawings are taken from an apparatus of each kind of my own,-they are made of tin, for want here of a fitter material, and are painted outside of a grass-green colour. The confectioner abovementioned laid in a stock of a hundred weight of each of the articles; viz. sal ammoniac and nitre; the former at the rate of one shilling per pound, and the nitre at fourpence--which of course when mixed, was at the moderate price of only eightpence per pound. Glauber's salts may be procured in the large way at the rate of about twopence per pound, and by the single pound at fourpence. The apparatus abovementioned may be only half or three parts filled for use; care must be taken in every instance that the surface of the subject to be acted upon be rather below the surface of the freezing mixture.

For cooling wine, the coldest water drawn from a pump will be quite sufficient; however, if required, a small portion of the cooling powder may be added to the water.

The addition of Glauber's salt, it may be observed, increases the density of the mixture, which then becomes a better conductor of the cold, if I may so express myself, and moreover retains the same temperature longer: of course it will be better of the two to overcharge than undercharge the proportion of the salts to the water. It will be apparent, for obvious reasons, that the part containing the subject to be cooled should be as thin as may be, and the whole of the external part in every apparatus thick.

This detail may probably appear prolix to any person in- 
duced by curiosity only to look it over; but to any one who means to put it in practice, the whole will be found essential, and with a little attention and experience become familiar and easy, and in which I have endeavoured to combine every advantage the subject will admit of; and as coming from the "fountain head," it may not prove uninteresting to some at least of your numerous readers. I am, Gentlemen,

Your most obedient servant,

Oxford, April 28, 1828.

RICHARD WALKER.

LXIII. On the Causes of Single and Erect Vision*. By L*** $\mathrm{M} * * * \mathrm{~S}^{*} * * * * * * *+\dagger$

$\mathrm{N}$ order to understand aright the reason of single and erect vision, it is necessary first of all to perceive the truth of certain metaphysical positions in relation to vision, without the establishment of which, confused ideas, hypothetical assumptions, and inconclusive reasonings on optical experiments and facts are presented to the mind, and tend to embarrass the simplicity of that truth which might otherwise be immediately revealed.

First,-Vision is a consciousness in the mind, and its next proximate cause must be a power equal to its production, and which unites it to the material world.

Secondly, -Vision of one colour only can never yield the vision of figure, because the proximate cause of the vision of figure is a line of demarcation formed by the sensation of the junction of two colours.

Thirdly,-The physical impulse producing such consciousness of colouring, is an equal proportional variety upon the retina of an eye; one eye alone being first supposed, as it is truly efficient to yield the idea of figure.

Fourthly,-An object cannot bein two placesat the same time.

Fifthly,-An object cannot exist and put forth its action where it is not.

These premises being supposed to be granted, let the question be asked, Why with two eyes given, two objects are not seen, although there be but one object given externally?

The answer (when supported by the foregoing premises, and conjoined with certain optical facts with which all who are conversant with the subject, are acquainted) will be, because there is not presented to the mind that variety of colouring which is necessary and alone efficient as the next proximate cause of vision; that is, there are not two lines of separate demarcation between two objects, but one line of demar-

* Communicated by a friend of the Author.

t Author of "An Essay on the Relation of Cause and Effect;" and of " Essays on the Perception of an External Universe," \&c. 